\title{
Sağlık Bilimleri Fakültesi Öğrencilerinin Madde Kullanımı, Ruhsal Durumu ve Şiddet Eğilim Düzeyleri
}

\author{
Nesibe GÜNAY MOLU ${ }^{1}$ (iD) Filiz HİSAR ${ }^{2}$
}

${ }^{1}$ Necmettin Erbakan Üniversitesi, Hemşirelik Fakültesi, Hemşirelik Bölümü, Konya, Türkiye, nesibegunaymolul@gmail.com (Sorumlu Yazar/Corresponding Author)

${ }^{2}$ Necmettin Erbakan Üniversitesi, Hemşirelik Fakültesi, Hemşirelik Bölümü, Konya, Türkiye,

filiz.hisar@mail.com

\begin{tabular}{|c|c|}
\hline Makale Bilgileri & ÖZ \\
\hline $\begin{array}{l}\text { Anahtar Kelimeler: } \\
\text { Alkol Madde Kullanımı, } \\
\text { Şiddet Eğilimi, } \\
\text { Ruhsal Durum, } \\
\text { Üniversite Öğrencileri. }\end{array}$ & 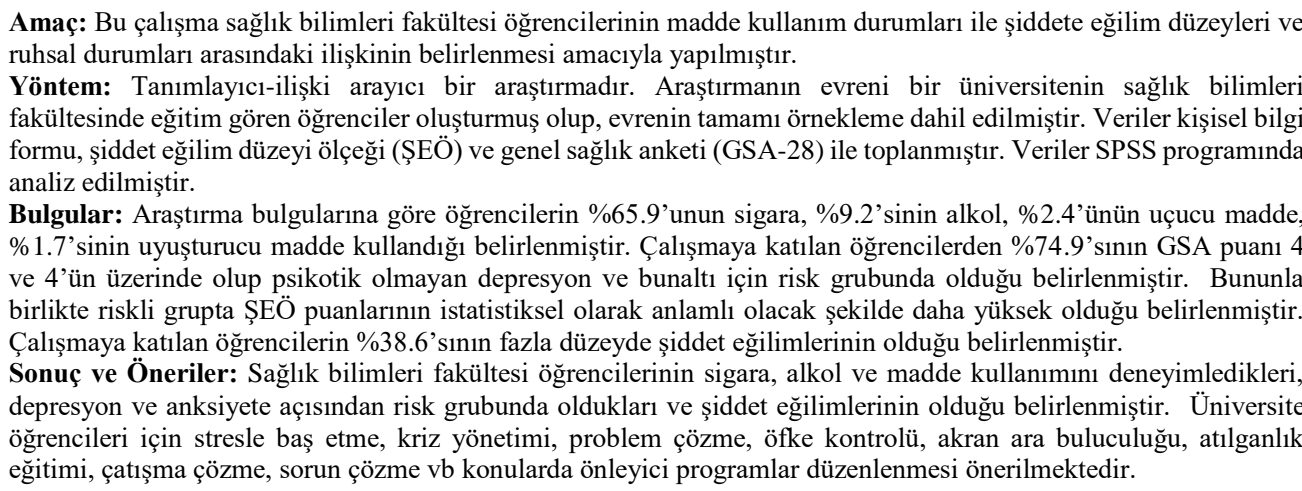 \\
\hline
\end{tabular}

\section{Substance Use, Mental State and Violence Tendency Levels of Faculty of Health} Sciences Students

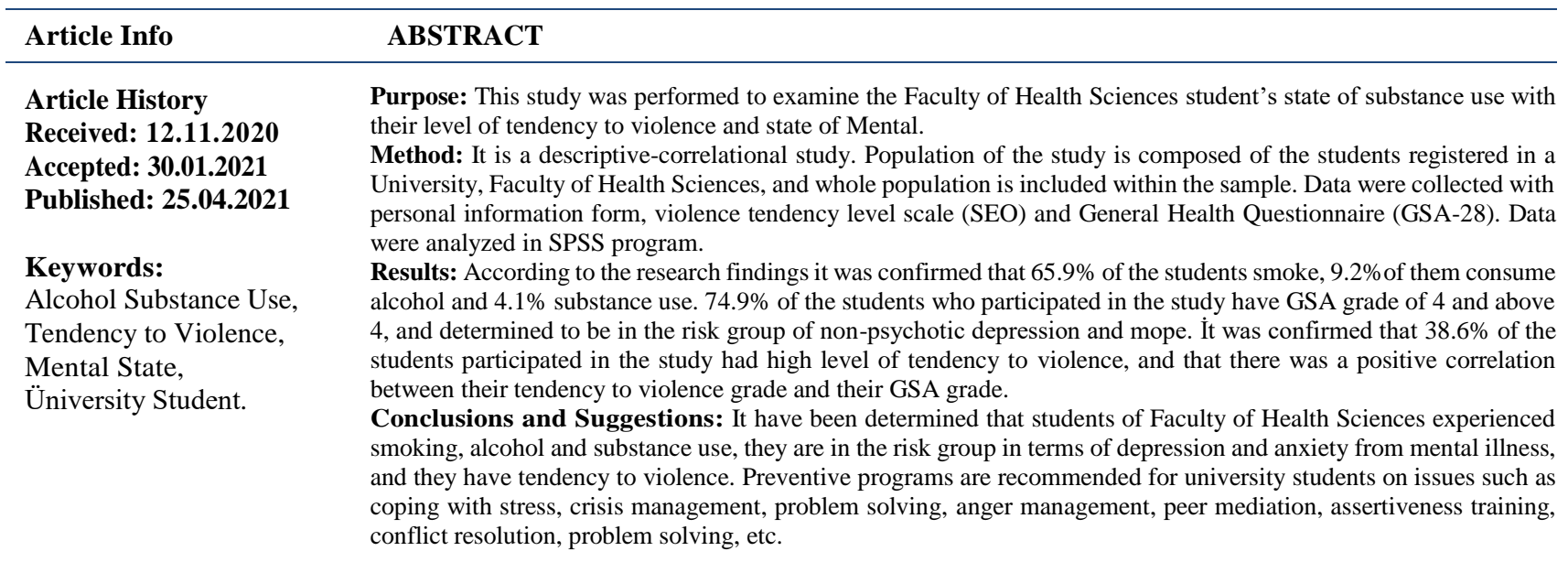

Atıf/Citation: Günay Molu, N. \& Hisar, F. (2021). Sağlık Bilimleri Fakültesi Öğrencilerinin Madde Kullanımı, Ruhsal Durumu ve Şiddet Eğilim Düzeyleri, Genel Sağllk Bilimleri Dergisi, 3(1), 29-40. 


\section{GíRiş}

Tüm dünyada ve ülkemizde bağımlılık yapıcı maddelerin kullanımı giderek önem kazanan bir halk sağlığı sorunudur. Bağımlılık yapıcı maddelerin kullanımı yaş ile birlikte devam etmekte, maddeyi ilk deneme ile başlayan ve bağımlılığa kadar ilerleyebilen bir madde kullanım bozukluğuna dönüşebilmektedir. Bağımlılık yapıcı ve madde kullanımı ile ilişkili bozukluklara neden olan maddeler Amerikan Psikiyatri Birliği'nin yaptı̆̆ı Ruhsal Bozuklukların Tanısal Sınıflandırmasına (Diagnostic and Statistical Manual of Mental Disorders-5: DSM-5) göre 10'a ayrılmaktadır. DSM-5'teki sinıflandırma; alkol, kafein, nikotin, esrar, halusinojenler, inhalanlar, opiyatlar, sedatif-hipnotik ve anksiyolitikler, stimulanlar ve diğer (ya da bilinmeyen maddeler) şeklindedir (Türkiye Uyuşturucu ve Uyuşturucu Bağımlılığı İzleme Merkezi (TUBİM) Raporu; Güleç ve ark., 2015). Sınıflandırmaya bakıldığında yasa dışı olan uyuşturucu maddeler yer alırken, tütün ve alkol yasa dışı olmayan, bağımlılık yapan maddeler arasında bulunmaktadır. Genellikle yaptıkları etkilere göre sınıflandırılan maddeleri bir grup ismi altında toplama bağımlılık alanında profesyonel çalışma yapmayanların konuyu daha iyi kavramalarını sağlayacağı düşünülmekte ve çalışmalarda bağımlılık yapan maddeler olarak kullanılmaktadır (Uzbay, 2016; Güleç ve ark., 2015). Bağımlılık yapıcı madde kullanım oranları her geçen gün artmakta ve 15-64 yaş grubunda dünya nüfusunun \%5.6'sının, Avrupa Birliği'nde yetişkin nüfusunun \%29'unun ve Türkiye'de \%3.1'inin uyuşturucu/uyarıc1 maddeyi en az bir defa denediği bildirilmiştir (The United Nations Office on Drugs and Crime 2019; TUBİM, 2018).

Bağımlılık yapıcı diğer maddelere göre sigaranın daha kolay ulaşılabilir olması, ucuz olması ve toplumsal açıdan daha kabul edilebilir olması ve çevresinde bulunan diğer kişiler arasındaki kullanım yaygınlığı sigara kullanılmasında önemli rol oynamaktadır (On Birinci Kalkınma Planı 2019-2023). Sigara gibi alkol kullanımı da her geçen yıl artmaktadır. Ülkemizde alkol kullanım sıklı̆̆ $1 \% 12.2$ olarak belirtilmiştir. Dünya Sağlık Örgütü (DSÖ)'nün 2014 y1lındaki “Alkol ve Sağlık Küresel Durum Raporu” verilerine göre alkol, 2012 y1lındaki tüm ölümlerin yaklaşık \%5.9'undan sorumludur. Dünya Sağl1k Örgütünün aralarında Türkiye'nin de olduğu 30 ülkede yaptığı araştırmada cinayet ve şiddet vakaları ile trafik kazalarının en önemli nedeni alkol olarak açıklanmıştır (On Birinci Kalkınma Planı 2019-2023; Türkiye İstatistik Kurumu 2016).

Alkol veya madde kullanımı, bireyde birçok probleme neden olmakla birlikte, bireyin arkadaşlarını, ailesini ve içinde bulunduğu toplumu da her alanda etkilemektedir (Merrin ve ark., 2018; Towsend, 2016; Y1lmaz ve ark., 2014). Alkol ve madde kullananlarda uyku ve yeme bozuklukları, depresyon, anksiyete bozuklukları, kişilik bozuklukları, paranoid bozukluklar, nevrotik eğilim, psikotik belirtiler ve bazı psikiyatrik bozukluklar daha fazla görülmektedir (TUBİM, 2019; Merrin ve ark., 2018).

Alkol ve madde kullanımı psikiyatrik bozuklukların gelişim riskini artırmakla birlikte, kullanımı sebebiyle ortaya çıkan problemlerden dolayı birçok yükü beraberinde getirdiği gibi şiddet ve suç eğilimini de artırmaktadır (Erdal ve ark., 2013). Bireylerde madde kullanımının varlığı psikiyatrik hastalıklara göre şiddet içeren davranışlar için daha yüksek risk oluşturmaktadır (Eronen ve ark., 1998; Sutherland ve ark., 2015). Aynı zamanda alkol ve madde kullanımı, anksiyete belirtilerini (Pereira Morales ve ark., 2017), saldırganlık ve öfke düzeylerini (Kaplan ve Çuhadar, 2020) de artırmaktadır Turhan ve ark. (2011)'nın üniversite öğrencileri ile yaptıkları çalışmada; sigara, alkol ve madde kullananlarda şiddet uygulama ve şiddete maruz kalma oranının kullanmayanlara göre daha yüksek olduğu belirtilmiştir. Bunun yanında şiddete maruz kalan üniversite öğrencilerinde anksiyete ve depresyon görülme riski yüksektir (Assari \& Lankarani, 2018). Kaplan ve Çuhadar (2020) yaptıkları çalışmada madde kullanan ergenlerde saldırganlık ve öfke düzeyinin çok yüksek olduğunu, Şahin Baltacı ve Altan (2016) gençler üzerinde yaptığı çalışmada ise depresyon belirtileri ile şiddet eğilimleri arasında pozitif ilişki olduğunu bildirmişlerdir.

Çocukluk döneminin geride bırakıldığı ve erişkinliğe ilk adımın atıldığı gençlik dönemi, bireyin hayatındaki en önemli süreçlerden biridir. Fiziksel ve psikolojik değişimler ile birlikte üniversite hayatının başlaması, evden ayrılması, yalnız kalma düşünceleri, farklı çevreye uyum sağlamaya çalışma, ekonomik problemler ve akademik problemler gençleri farklı alışkanlıklara yöneltebilmektedir (Erdal ve ark., 2013; Erkan ve ark., 2012; Turhan ve ark., 2011). 2019 yılındaki TUBİM verilerine göre maddeyi hayatında en az bir kere kullananların yaş gruplarına göre dağılımına bakıldığında \%35.4'ünün 15-24 yaş aralığında yoğunlaştığı ve yaş ortalamasının 19 olduğu görülmektedir. Madde kullanımı ve sigara kullanımı ile ilgili çalışmalar daha çok ilköğretim ve lise dönemi 
öğrencilerini kapsasa da (Turhan ve ark., 2011) TUBİM 2019 verilerine göre maddeyi ilk kullananların \%9.8'i üniversite öğrencisi olarak belirlenmiştir. Bu veriler doğrultusunda üniversite öğrencilerinin madde kullanımı açısından risk altında olduğu görülmektedir.

Madde kullanım riski olan gruplara yönelik hemşirelik girişimleri koruyucu müdahaleler ile başlamaktadır. Madde kullanımını önlemeye yönelik ve şiddet ile suça eğilime yönelmeyi engelleyici koruyucu önlemler alınabilir. Özellikle toplum ruh sağlığı ve okul sağlığı alanında çalışan hemşirelerin, riskli grupların sağlık kontrollerinin yapılması, madde kullanım problemlerinin tanımlanması, madde kullanımının önlenmesine yönelik eğitimlerin verilmesi ile farkındalık oluşturulması, danışmanlık hizmetlerinin verilmesi, diğer sektörler ile ortak çalışmaların yürütülmesi ve ihtiyaç halinde gerekli bakım ve tedavi için uygun yaklaşımların belirlenmesine yönelik rol ve sorumlulukları bulunmaktadır (Albayrak ve Balcı, 2014; Baysan Arabacı ve ark., 2017).

Literatüre bakıldığında üniversite öğrencilerinde psikolojik faktörler, şiddet ve madde kullanım durumları ile ilgili ayrı ayrı çalışmalar yer alırken (Baran ve ark., 2014; Erdal ve ark., 2013; Özgür ve ark., 2011) aralarındaki ilişkiyi inceleyen yeterli çalışmaya rastlanmamıştır (Turhan ve ark., 2011). Bu nedenle bu çalışmada Sağlık Bilimleri Fakültesi öğrencilerinin madde kullanım durumları, ruhsal durumları ile şiddete eğilim düzeylerinin belirlenmesi amaçlanmıştır.

\section{Araştırma Soruları}

- Sağlık bilimleri fakültesi öğrencilerinin genel sağlık durumları nedir?

- Sağlık bilimleri fakültesi öğrencilerinin şiddet eğilim düzeyleri nedir?

- Sağlık bilimleri fakültesi öğrencilerinin madde kullanım alışkanlıkları bazı sosyodemografik özelliklere göre değişmekte midir?

- Sağlık bilimleri fakültesi öğrencilerinin şiddet eğilim düzeyleri, bazı sosyodemografik ve madde kullanım alışkanlıklarına göre değişmekte midir?

- Sağlık bilimleri fakültesi öğrencilerinin genel ruhsal durumları, bazı sosyodemografik ve madde kullanım alışkanlıklarına göre değişmekte midir?

- Sağlık bilimleri fakültesi öğrencilerinin genel ruhsal durumları ve şiddet eğilim düzeyleri arasında ilişki var midir?

\section{YÖNTEM}

\section{Araştırma Modeli}

Tanımlayıcı-ilişki arayıcı bir araştırmadır.

\section{Araştırmanın Evren ve Örneklemi}

Araştırmanın evrenini bir kamu üniversitesinin Sağlık Bilimleri Fakültesinde kayıtlı 573 öğrenci oluşturmaktadır. Araştırmada örneklem seçimine gidilmemiş, araştırmanın örneklemini araştırmaya katılmayı kabul eden, araştırmanın yapıldığ ders saatinde derse devam eden ve veri toplama formunu eksiksiz dolduran 422 öğrenci (\%73.64) oluşturmuştur.

\section{Veri Toplama Araçları ve Süreçleri}

Araştırma verileri her sınıf için uygun olan ders saatinde ders başlamadan önce kişisel bilgi formu, Şiddet Eğilim Düzeyi Ölçeği ve Genel Sağlık Anketi ile 07-21 Aralık 2015 tarihleri arasında toplanmıştır. Her sınıfa bir defa gidilmiş ve o gün derste olan öğrenciler araştırmaya dahil edilmiştir. Her formun uygulanması yaklaşı $15 \mathrm{dk}$ sürmüş ve öğrenciler formları kendileri doldurmuştur.

\section{Bağımlı değişkenler}

Şiddet eğilim ölçeği, genel sağlık anketi. 


\section{Bağımsız değişkenler}

Yaş, anne babanın eğitim durumu, bölümü, ailenin aylık gelir düzeyi, yaşadığı yer, harçlığını kimden aldığı, sigara deneyimleme durumu, geçen ay sigara kullanma durumu, alkol deneyimleme durumu, geçen ay alkol kullanma durumu, uçucu madde deneyimleme durumu, uyuşturucu madde deneyimleme durumu, anne babasının sigara kullanma durumu, akrabalarında bağımlılık yapıcı madde kullanım durumları.

\section{Kişisel Bilgi Formu}

Literatür taranarak oluşturulmuştur. Öğrencilerin sosyodemografik bilgilerini (yaş, anne babanın eğitim durumu, bölümü, ailenin aylık gelir düzeyi, yaşadığı yer, harçlığını kimden aldığı) ve öğrencilerin madde kullanım alışkanlıklarını içeren (sigara deneyimleme, geçen ay sigara kullanma, alkol deneyimleme, geçen ay alkol kullanma, uçucu madde deneyimleme, uyuşturucu madde deneyimleme, anne babasının sigara kullanma, akrabalarında bağımlılık yapıcı madde kullanım durumları) kişisel bilgi formu iki bölümden oluşmaktadır (Alaçam ve ark., 2015; Ulaş ve ark., 2015; Turhan ve ark., 2011; Robert ve ark., 2010; Mayda ve ark., 2009).

\section{Şiddet Ĕ̆ilim Ölçeği (ŞEÖ)}

Milli Eğitim Bakanlığı için yürütülmüş olan “Orta Öğretim Kurumlarında Okuyan Öğrencilerin Saldırganlık ve Şiddet Eğilimleri” başlıklı araştırmada kullanılmak üzere Göka, Bayat ve Türkçapar tarafından 1995 yılında geliştirilmiştir. Ölçeğin güvenirliğini sınamak üzere iç tutarlılık kapsamında güvenilirlik katsayısı iki farklı zamanda .78-.87 bulunmuştur. Ölçek 20 maddeden oluşmakta ve "Hiç Uygun Değil”, "Biraz Uygun”, "Uygun”, "Çok Uygun" seçenekleri ile 4'lü likert tiptedir. Ölçekten en düşük 1, en yüksek 80 puan alınmaktadır. Öğrencilerin ölçekten aldıkları puanlara göre, 1-20 arası puan "çok az", 21-40 arası puan "az", 41-60 arası puan "fazla" ve 61-80 arası puan "çok fazla" şiddet eğilimi olarak değerlendirilmiştir (Başbakanlık Aile Araştırma Kurumu Başkanlığı, 1998).

\section{Genel Sağlık Anketi (GSA-28)}

David Goldberg (1970) y1lında geliştirilmiştir. Ölçeğin 12, 28, 30 ve 60 soruluk biçimleri olduğu bilinmektedir. Ülkemizde Türkçe'ye uyarlama çalışması için 12 ve 28 soruluk formları kullanılmış ve 1996 yılında K1lıç tarafından yapılmıştır. Ölçeğin iç tutarlılığı 0.84 , duyarlılığg 0.74 , özgüllüğğ 0.70 bulunmuştur. Ölçek psikotik olmayan depresyon ve bunaltı riskinin belirlenmesi için kullanılmaktadır. Son birkaç haftadaki durum düşünülerek soruların cevaplanması gerekmektedir ve ölçek 4'lü likert tiptedir (0: hiç olmuyor, 1: her zamanki kadar, 2: her zamankinden sık, 3: çok sık). Ölçek puanı hesaplanırken, ilk iki sütun "0", son iki sütun "1" olarak puanlanmakta ve 4 ve üzeri puan alanlar riskli olarak kabul edilmektedir.

\section{Verilerin Analizi}

Veriler SPSS programında sayı, yüzde, Ki kare, Spearman's korelasyon katsayısı ve İki değişkenli ölçümlerde Mann Whitney U, ikiden fazla değişkeni olan ölçümlerde Kruskall Wallis testleri yapılmıştır. Kruskall Wallis testi sonucunda istatistiksel olarak anlamlı çıkan durumlarda ikili karşılaştırmalar için Mann Whitney U testi yapılmıştır.

\section{Etik}

Araştırma için ilgili kurumdan yazılı izin ve katılımcılardan sözlü onam alınmıştır.

\section{BULGULAR}

Çalışmaya katılan öğrencilerin \%40.5'i hemşirelik öğrencisi, \%76.8'i kadın, \%94.3'ünün annesi babası să̆ ve \%91'i ailesi ile birlikte yaşıyor, büyük çoğunluğunun anne babasının eğitim düzeyi ilköğretim düzeyinde (anne \%83.2; baba \%55.7), \%60.2'si gelirini giderine denk olarak değerlendirilmekte, \%80.1'i harçlığını ailesinden aldığını ifade etmiştir.

Bununla birlikte madde kullanım oranlarına bakıldığında; \%65.9'unun sigara kullanımını deneyimlediği, \%85.8'inin geçen ay boyunca hiç sigara kullanmadığı, \%13.5'unun geçtiğimiz ay günde yarım paketten daha az sigara kullandığı, \%9.2'sinin alkol kullanımını deneyimlediği, \%94.3'ünün hiç sarhoş olmadığı, \%2.4'ünün uçucu 
madde kullanımını deneyimlediği, \%1.7'sinin uyuşturucu madde kullanımını deneyimlediği, \%46.9'unun anne babasının sigara, \%4.5'unun alkol kullandığı ve \%6.6'sının akrabalarında uyuş̧urucu madde kullanımının olduğu belirlenmiştir.

Tablo 1. Öğrencilerinin Bazı Sosyodemografik Özellikleri ile Madde Kullanım Alışkanlıklarının Karşılaştırılması

\begin{tabular}{|c|c|c|c|c|c|c|}
\hline & EVET & \multicolumn{2}{|c|}{ HAYIR } & TOTAL & $\mathbf{X}^{2}$ & $\mathbf{P}$ \\
\hline \multicolumn{7}{|l|}{ Hiç sigara içtiniz mi? } \\
\hline \multicolumn{7}{|l|}{ Bölüm } \\
\hline Beslenme ve Diyetetik & $46(\% 82.1)$ & \multicolumn{2}{|c|}{$10(\% 17.9)^{*}$} & 56 & 22.069 & 0.001 \\
\hline Hemşirelik & $111(\% 64.9)$ & \multicolumn{2}{|c|}{$60(\% 35.1)$} & 171 & & \\
\hline Fizik Tedavi ve & $52(\% 80.0)$ & \multirow{2}{*}{\multicolumn{2}{|c|}{$13(\% 20.0)$}} & 65 & & \\
\hline Rehabilitasyon. & & & & 78 & & \\
\hline Sosyal Hizmet & $26(\% 51.0)$ & \multicolumn{2}{|c|}{$25(\% 49)$} & 51 & & \\
\hline \multicolumn{7}{|l|}{ Cinsiyet } \\
\hline Kadın & $231(\% 71.3)$ & \multicolumn{2}{|c|}{$93(\% 28.7)$} & 324 & 18.229 & 0.000 \\
\hline Erkek & $47(\% 48.0)$ & \multicolumn{2}{|c|}{$51(\% 52)$} & 98 & & \\
\hline \multicolumn{7}{|c|}{ Yaşam boyu alkol kullanma durumu } \\
\hline Kadın & $23(\% 7.1)$ & \multicolumn{2}{|c|}{$301(\% 92.9)$} & 324 & 9.11 & 0.003 \\
\hline Erkek & $16(\% 16.3)$ & \multicolumn{2}{|c|}{$82(\% 83.7)$} & 98 & & \\
\hline \multicolumn{7}{|c|}{ Uyuşturucu madde deneyimleme durumları } \\
\hline Kadın & $2(\% 0.6)$ & \multicolumn{2}{|c|}{$322(\% 99.4)$} & 324 & 9.255 & 0.009 \\
\hline Erkek & $5(\% 5.1)$ & \multicolumn{2}{|c|}{$93(\% 94.9)$} & 98 & & \\
\hline \multicolumn{7}{|c|}{ Geçen ay sigara kullanma durumu } \\
\hline Cinsiyet & Hiç & Ara sira & Her gün & Total & $\mathbf{X}^{2}$ & $\mathbf{P}$ \\
\hline Kadin & $295(\% 91.0)$ & $18(\% 5.6)$ & $11(\% 3.4)$ & 324 & 36.31 & 0.000 \\
\hline Erkek & $67(\% 68.4)$ & $12(\% 12.2)$ & $19(\% 19.4)$ & 98 & & \\
\hline \multicolumn{7}{|l|}{ Annenin eğitim durumu } \\
\hline İlköğretim & $306(\% 87.2)$ & $23(\% 6.6)$ & $22(\% 6.3)$ & 351 & 9.572 & 0.048 \\
\hline Ortaöğretim & $42(\% 85.7)$ & $3(\% 6.1)$ & $4(\% 8.2)$ & 49 & & \\
\hline Yükseköğretim & $14(\% 63.6)$ & $4(\% 18.2)$ & $4(\% 18.2)$ & 22 & & \\
\hline
\end{tabular}

$\mathrm{P}<0.05, \quad \mathrm{X}^{2}:$ Ki Kare analizi

Tablo 1'de Sağlık Bilimleri Fakültesi öğrencilerinin beslenme ve diyetetik bölümünde öğrenim görenlerin $(\mathrm{n}=46, \% 82.1, \mathrm{p}=0.001)$ ve cinsiyeti kadın olanların $(\mathrm{n}=23, \% 7.1, \mathrm{p}=0.000)$ sigara kullanımı deneyimleme durumlarının yapılan ki kare testine göre anlamlı derecede yüksek olduğu, yaşam boyu alkol kullanma ( $\mathrm{n}=16$, $\% 16.3, \mathrm{p}=0.003)$ ve uyuşturucu madde deneyimleme $(\mathrm{n}=5, \% 5.1, \mathrm{p}=0.009)$ düzeylerinin erkeklerde daha yüksek olduğu bulunmuştur. Bununla birlikte geçen ay her gün sigara kullanan öğrencilere bakıldığında yapılan ki kare analizi sonuçlarına göre erkek öğrenciler $(n=19, \% 19.4, \mathrm{p}=0.000)$ ve annesinin eğitim durumu yükseköğretim $(\mathrm{n}=4$, \%18.2, p=0.048) olanlar istatistiksel olarak anlamlı çıkacak şekilde yüksek bulunmuştur. Öğrencilerin yaş1, babanın eğitim durumu, aylık gelir düzeyi, yaşadığı yer, harçlığını kimden aldığı değişkenleri ile madde kullanım alışkanlıkları arasında fark bulunmamaktadır.

Tablo 2. Öğrencilerin ŞEÖ ve GSA Puanlarının Sinıflandırılması

\begin{tabular}{lcc} 
ŞEÖ GRUP & $\mathbf{n}$ & $\mathbf{\%}$ \\
\hline $1-20$ çok az & 0 & 0 \\
$21-40 \mathrm{az}$ & 248 & 58.8 \\
$41-60$ fazla & 163 & 38.6 \\
61-80 çok fazla & 11 & 2.6 \\
Toplam & 422 & 100.0 \\
\hline GSA GRUP & & \\
\hline Sağliklı grup (<4 puan) & 106 & 25.1 \\
Riskli grup ( 4 puan ve üzeri) & 316 & 74.9 \\
\hline
\end{tabular}


Tablo 2'de çalışmaya katılan öğrencilerin şiddet eğilim ölçeğinden aldıkları puana göre şiddet eğilim düzeyleri belirlenmiştir. 1-20 puan alan yani çok az şiddete eğilimi olan öğrenci bulunmazken, \%58.8'inin az düzeyde şiddete eğilimlerinin, \%38.6'sının fazla düzeyde şiddet eğilimlerinin, \%2.6'sının ise çok fazla şiddet eğilimlerinin olduğu belirlenmiştir. Çalışmaya katılan öğrencilerden \%74.9'unun GSA puan1 4 ve 4'ün üzerinde olup psikotik olmayan depresyon ve bunaltı için risk grubunda olduğu belirlenmiştir.

Tablo 3. Öğrencilerin Bazı Sosyodemografik Özellikleri ve Madde Kullanım Alışkanlıklarına Göre ŞEÖ ve GSA Puanlarının Karşılaştırılması

\begin{tabular}{|c|c|c|c|c|c|c|c|}
\hline & \multicolumn{3}{|c|}{ ŞEÖ PUANI } & \multicolumn{3}{|c|}{ GSA PUANI } & \multirow[b]{2}{*}{$\mathbf{P}$} \\
\hline & $\mathbf{N}$ & Ort \pm SS & $\mathbf{U}-\mathbf{K W}$ & $\mathbf{P}$ & Ort \pm SS & $\mathbf{U}$ & \\
\hline \multicolumn{8}{|l|}{ Cinsiyet } \\
\hline Kadın & 324 & $39.00 \pm 8.16$ & 11144.0 & 0.001 & $76.67 \pm 5.35$ & 15071.5 & 0.446 \\
\hline Erkek & 98 & $42.37 \pm 9.42$ & & & $6.93 \pm 4.87$ & & \\
\hline \multicolumn{8}{|c|}{ Babanın eğitim durumuna göre } \\
\hline İlk Öğretim & 235 & $38.29 \pm 7.95$ & 3.849 & 0.146 & $7.48 \pm 5.21$ & 6.594 & $\mathbf{0 . 0 3 7}$ \\
\hline Orta öğretim & 109 & $40.93 \pm 9.16$ & & & $8.05 \pm 5.43$ & & \multirow{2}{*}{$\begin{array}{l}\text { Farklilik } \\
2-3\end{array}$} \\
\hline Yüksek öğretim & 78 & $40.28 \pm 8.10$ & & & $6.22 \pm 4.72$ & & \\
\hline \multicolumn{8}{|c|}{ Aylık gelir düzeyine göre } \\
\hline Gelir giderden az & 101 & $40.86 \pm 8.35$ & 4.501 & 0.105 & $9.29 \pm 5.84$ & 0.105 & 0.001 \\
\hline Gelir gidere denk & 254 & $39.06 \pm 8.74$ & & & $6.68 \pm 4.65$ & & \multirow{2}{*}{$\begin{array}{l}\text { Farklilik } \\
1-2\end{array}$} \\
\hline Gelir fazla & 67 & $40.85 \pm 8.08$ & & & $7.88 \pm 5.81$ & & \\
\hline \multicolumn{8}{|c|}{ Geçtiğimiz ay sigara kullanma durumu } \\
\hline Hiç & 362 & $39.32 \pm 8.26$ & 7.398 & 11.17 & $7.30 \pm 5.06$ & 0.025 & 0.004 \\
\hline Ara sira & 30 & $40.06 \pm 8.24$ & & & $7.50 \pm 7.21$ & & \multirow{2}{*}{$\begin{array}{l}\text { Farklilik } \\
2-3\end{array}$} \\
\hline Her gün & 30 & $41.00 \pm 10.0$ & & & $9.88 \pm 4.79$ & & \\
\hline \multicolumn{8}{|c|}{ Geçtiğimiz ay alkol kullanma durumu } \\
\hline Hiç & 408 & $39.50 \pm 8.34$ & 8.114 & 0.004 & $7.33 \pm 5.19$ & 11.197 & 0.001 \\
\hline Ara sira & 14 & $46.61 \pm 11.31$ & & & $11.92 \pm 5.33$ & & \\
\hline \multicolumn{8}{|c|}{ Akrabaların uyușturucu kullanma durumu } \\
\hline Evet & 28 & $42.17 \pm 10.61$ & 4778.0 & 0.244 & $9.77 \pm 4.00$ & 3435.0 & 0.001 \\
\hline Hayır & 393 & $39.59 \pm 8.40$ & & & $7.33 \pm 5.30$ & & \\
\hline
\end{tabular}

p<0.05 Ort:Ortalama, SS: Standart Sapma, U: Mann Whitney U, KW: Kruskal Wallis

Tablo 3’te öğrencilerin ŞEÖ puanları erkeklerin kadınlara göre ( $\mathrm{p}=0.001)$ anlamlı derecede yüksek bulunmuştur. GSA puanları babanın eğitim durumu ortaöğretim olanların yükseköğretim olanlara göre ( $\mathrm{p}=0.037)$, aylık geliri giderinden az olanların aylık geliri giderine denk olanlara göre $(\mathrm{p}=0.001)$, her gün sigara kullananların, ara sıra kullananlara göre ( $\mathrm{p}=0.004)$, akrabalarında uyuşturucu kullanımı olanların olmayanlara göre $(\mathrm{p}=0.001)$ istatistiksel olarak anlamlı olacak şekilde yüksek olduğu belirlenmiştir. Ayrıca geçtiğimiz ay ara sıra alkol kullananların hiç kullanmayanlara göre hem ŞEÖ $(p=0.004)$ hem de GSA ( $p=0.001)$ puanlarının istatistiksel olarak anlamlı olacak şekilde yüksek olduğu tespit edilmiştir. Öğrencilerin yaşı, bölümü, annenin eğitim durumu, yaşadığ yer, harçlığını kimden aldığı değişkenleri ile ŞEÖ ve GSA puanları arasında fark bulunmamaktadır.

Tablo 4. Şiddet Ĕ̌gilimi Ölçeği ve Genel Să̆llk Anketi Arasındaki İlişki

\begin{tabular}{lccc}
\hline & & ŞEÖ & GSA \\
\hline Şiddet Eğilimi Ölçeği & $\mathrm{r}$ & 1.000 & $0.354^{* *}$ \\
& $\mathrm{p}$ & $\mathrm{n}$ & 0.000 \\
& $\mathrm{n}$ & 422 & 422 \\
\hline
\end{tabular}

**. Correlation is significant at the 0.01 level (2-tailed). 
Şiddet Eğilim Ölçeği ve Genel Sağlık Anketi puanları arasındaki ilişkiyi belirlemek amacıyla yapılan Spearman's korelasyon katsayı tekniği sonucunda değişkenler arasında ŞEÖ puanı ve GSA puanı arasında anlamlı ve zayıf pozitif yönlü ilişki $(r=0.354, p<0.000)$ olduğu belirlenmiştir.

\section{TARTIŞMA}

Tüm dünyada ve ülkemizde giderek artan madde kullanımı ve bununla birlikte ortaya çıkan problemler bireylerin şiddet düzeylerini ve ruhsal durumlarını etkilemektedir. Çalı̧̧maya katılan üniversite öğrencilerinin sigara, alkol ve uçucu/uyuşturucu maddeyi deneyimleme oranlarının sırası ile \%65.9; \%9.2; \%2.4; \%1.7 olduğu ve bu oranların erkeklerde daha yüksek görüldügü belirlenmiştir. Yapılan çalışmalarda sigara kullanım oranı \%33.3 ve $\% 73.3$, alkol kullanım oranı $\% 26.3$ ve $\% 70.8$, uçucu ve uyuşturucu madde kullanım oranı $\% 1.78$ ve $\% 6.3$ arasında yer almaktadır (Göney ve ark., 2020; Straus ve ark., Cornelius ve ark., 2019; TUBİM 2019; Alaçam ve ark., 2015; Turhan ve ark., 2011; Evren ve ark., 2011; Mayda ve ark., 2009; Kolay Akfert ve ark., 2009; Yalçın ve ark., 2009). Avrupa'daki madde kullanımına ilişkin en kapsamlı çalışma olan, 24'ü Avrupa Birliği üyesi toplamda 35 Avrupa Ülkesinde yapılan 96046 öğrencinin dahil edildiği çalışma sonuçlarına göre her gün sigara kullanım oranı $\% 21$, son bir ayda alkol kullanım oran $1 \% 47$ ve uyuşturucu madde kullanım oranı $\% 7.7$ olarak belirtilmiştir (ESPAD, 2015). Üniversite öğrencilerinde sigara, alkol ve madde kullanım sıklı̆̆ının erkeklerde daha yüksek olduğu bilinmektedir (Yıldız ve ark., 2020; Straus ve ark., 2019; TUBİM, 2019; Turhan ve ark., 2011; Yalçın ve ark., 2009). Bunun yanında alkol ve sigara kullanan bireylerin madde kullanım riskleri kullanmayanlara göre daha yüksek çıkmakta bu nedenle alkol ve sigara da madde kullanımı açısından risk kabul edilmektedir (Yiğit ve Öncü, 2020; Yalçın ve ark., 2009). Sigara ve alkol deneme oranının yaşına bakıldığında üniversite döneminde de az olmadığı (Kolay Akfert ve ark., 2009), çalışan gençlerde yapılan bir çalışmada 16 yaş ve üstünde maddeyi ilk kez deneyimlemenin $\operatorname{arttığ1~(Yiğit~ve~Öncü,~2020)~ve~bu~nedenle~önleme~ile~ilgili~çalışmalarının~üniversite~}$ öğrencilerinde de devam etmesi gerektiği vurgulanmaktadır (Kolay Akfert ve ark., 2009). Çalışma sonuçları literatür bulguları ile uyumludur.

Bu çalışmada öğrencilerden \% 74.9'unun psikotik olmayan depresyon ve bunaltı için risk grubunda olduğu belirlenmiştir (Tablo 2). Yapılan çalışmalarda ögrencilerde depresyon ve anksiyete görülme riski \%47 ve \%65 arasında değişmekte ve kızlarda erkeklere göre oranın daha yüksek olduğu bildirilmektedir (Yıldız ve ark., 2020; Uras ve ark., 2012; Üner ve ark., 2007). Yan ve ark. (2019)'1 hemşirelik öğrencilerinde, normal erişkinlere ve sağlık alanı dışındaki üniversite öğrencilerine göre psikiyatrik belirtilerin (somatizasyon, obsesif-kompulsif belirtiler, depresyon, anksiyete, korku ve psikoz) görülme oranının daha fazla olduğunu belirlemişlerdir. Depresyon ve anksiyete görülme riski yüksek olmasına rağmen yapılan çalışmalarda depresyon görülme oranı daha düşük seyretmekte ve \%18.2 ile \%38.3 arasında yer almaktadır (Ulaş ve ark., 2015; Evren ve ark., 2011; Mackenzie ve ark., 2011; Robert ve ark., 2010, Mayda ve ark., 2009). Anksiyete ve depresyon riskini birçok faktör etkilemekle birlikte bireylerin sosyoekonomik durumları, sigara alkol madde kullanımının varlığı ve anne babanın eğitim durumu etkileyen faktörler arasında yer almaktadır. Koruyucu hemşirelik yaklaşımları olarak etkileyen faktörlere göre risk gruplarının belirlenmesinin ve önleyici çalışmaların yapılmasının önemli olduğu düşünülmektedir.

Bu çalışmada aylık geliri düşük olanların GSA puanları anlamlı derecede yüksek bulunmuştur (Tablo 3). Yapılan çalışmalarda ailenin düşük gelir düzeyinin depresyon düzeyini artırdığı görülmektedir (Ulaş ve ark., 2015; İlhan ve ark., 2014; Mayda ve ark., 2009; Mikolajczyk ve ark., 2008; Üner ve ark., 2007; Bostanc1 ve ark., 2005; Kaya ve ark., 2007). Ekonomik durumun yetersiz olması öğrencilerin kaynaklara ulaşımını, gereksinimlerini karşılamalarını engellemekte ve bunlara bağlı olarak anksiyete ve depresyon düzeyini etkilediği düşünülmektedir.

Bu çalışmada sigara ve alkol kullanımının GSA puanları üzerinde etkili olduğu görülmektedir (Tablo 3). Sigara kullanan öğrencilerde depresyon görülme düzeyi kullanmayanlara göre daha fazla olmaktadır (Mackenzie ve ark., 2011; Üner ev ark., 2007; Robert ve ark., 2010; Lenz, 2004). Üner ve ark. (2007) yaptığ çalışmada erkek öğrencilerden halen alkol kullananların \%79.5'inin hiç kullanmayanların ise \%48.3'ünün GSA-12 puanları 2 ve üzerinde olup anlamlı farklılık saptanmış ve ruhsal durum açısından riskli grup olarak belirlenmiştir. Ünsal ve Tözün (2014) yaptıkları çalışmada sigara içenlerde içmeyenlere göre depresyon oranını daha yüksek belirlemişlerdir. Çalışma sonuçları literatür ile uyumludur. Bu nedenle sigara ve alkol kullanan bireylerin ruh 
sağlığı açısından riskli grup kabul edilmesinin ve koruyucu tedbirlerin alınmasının önemli olduğu düşünülmektedir.

Bu çalışmada öğrencilerin çoğunluğunun şiddet eğiliminde oldukları belirlenmiştir (Tablo 2). Gümüş ve ark. (2016) öğrenciler ile yaptıkları çalışmada \%57.3'ünün az düzeyde, \%40'ının yüksek, \%2.7'sinin çok yüksek düzeyde şiddet eğilimlerinin olduğunu bildirmişlerdir. Kul Uçtu ve Karahan (2016) sağlik bilimleri fakültesi öğrencilerinin orta düzeyde, Özcan ve ark (2020) ise lise öğrencilerinin fazla düzeyde şiddete eğilimlerinin olduğunu belirtmişlerdir. Şiddete maruz kalanların ve şiddeti uygulayan kişilerin her ikisinin de sağlı̆̆ olumsuz yönde etkilenmektedir. Bireylerde şiddet eğilimlerinin bulunması bazı davranış problemlerinin, olumsuz baş etme yöntemlerinin ya da psikiyatrik belirtilerin habercisi olarak değerlendirilebilir.

$\mathrm{Bu}$ çalışmada erkek öğrencilerde ve ara sıra alkol kullananlarda şiddet eğilimlerinin daha fazla olduğu görülmüştür (Tablo 3). Tosunöz ve ark. (2019)'1 sigara ve alkol kullanan üniversite öğrencilerinin şiddet eğilim puanlarının kullanmayanlara göre daha yüksek olduğunu belirtmişlerdir. Üniversite öğrencilerinde, madde kullanımı ile flört şiddeti arasında pozitif yönde ilişki olduğu ve madde kullanan öğrencilerde flört şiddeti uygulama ve maruz kalma oranının daha yüksek olduğu yapılan çalışmalarda bildirilmiştir (Straus ve ark., 2019; Taylor \& Sullivan, 2017). Zinnur Kılıç (2012) yaptığı çalışmada alkol kullanan öğrencilerin daha çok şiddet davranış1 gösterdiğini belirlemiştir. Alkol kullanımı ve şiddet eğilimi etkisiz baş etme yöntemi olarak değerlendirilebilir. Başetme becerileri yeterince gelişmemiş olan bireylerde olumsuz başetme yöntemlerinin kullanılmasının bu sonucun ortaya çıkmasında etkili olduğu düşünülmüştür. Yapılan çalışmalara bakıldığında erkeklerin şiddet eğilimlerinin ve şiddeti uygulama oranlarının daha yüksek olduğu görülmektedir (Özcan ve ark., 2020; Tosunöz ve ark., 2019; Haskan Avcı ve Yıldırım, 2015; Gümüş Babacan ve ark., 2015; Gençoğlu ve ark., 2014; Zinnur Kılıç, 2012; Evren ve ark., 2011). Erkek egemenliğinin fazla olduğu bir toplum yapısında olan ülkemizde şiddet eğiliminin de erkeklerde yüksek çıkması beklenen bir sonuçtur.

Şiddet Eğilim Ölçeği (ŞEÖ) puanları ve GSA puanları arasında pozitif yönlü ilişki olduğu belirlenmiştir. Cenata ve ark. (2018) yaptıkları çalışmada şiddete uğrayan öğrencilerde madde kullanım oranının daha yüksek olduğu ve psikolojik sağlı düzeyinin madde kullanım ve şiddete uğrama düzeyleri ile ilişkili olduğu bildirilmiştir. Straus ve ark. (2019)'nın yaptığı çalışmanın sonuçlarına göre flört şiddeti ve madde kullanımı olan bireylerde psikolojik sağlığı değerlendiren çalışmaların yapılmasını önermişlerdir.

Şiddet eğilimi yüksek olan ve şiddet uygulayan öğrenciler, sağlığını daha kötü algılamakta, öğrencilerin depresyon ve anksiyete düzeyleri daha yüksek olmaktadır (Evren ve ark., 2011; Robert ve ark., 2010; Üner ve ark., 2007). Haskan Avcı ve Yıldırım (2014)'ın yaptı̆̆ı çalışmada, şiddet eğilimi yüksek olan öğrencilerin yalnızlık düzeyleri daha yüksek, aile, öğretmen ve arkadaş desteklerinin daha düşük olduğunu belirlemişlerdir. Bu nedenle şiddet eğilim olan öğrencilerin ailelerinin ve üniversitedeki eğitmenlerin öğrencilere destekleyici yaklaşması ve bununla ilgili toplumda ve üniversitelerde psikoeğitimsel programların yürütülmesi önerilmektedir. Okul çağ çocuklarda ve adölösanlarda şiddet ve agresyon içeren davranışların azaltılabilmesi için, önlemeyi ve müdahaleyi içeren programların etkili olduğu ve başarı ile sonuçlandığı yapılan çalışmalarda görülmektedir (Donat Bacıoğlu, 2014). Okul kuralları ve politikaları ile şiddet oranlarının ve madde kullanım oranlarının azaltılabileceği bildirilmektedir (Shackleton ve ark., 2016). Okul sağlığı, ruh sağlı̆̆1 ve psikiyatri, halk sağlığ1 ve pediatri hemşireleri gibi sağlık profesyonellerinin bağımlılık yapıcı madde kullanımı, şiddet eğilimlerinin azaltılması ve ruhsal yönden desteklemeyi içeren önleyici çalışmalar yapması önem kazanmaktadır.

\section{SONUÇ VE ÖNERILER}

Bu çalışmada; sağlık bilimleri fakültesi öğrencileri arasında sigara, alkol ve madde kullanım oranları, ruhsal durumları ve şiddet eğilim düzeyleri belirlenmiş, aralarındaki ilişki incelenmiştir. Özellikle erkek olma, gelir düzeyinin düşük olması ve sigara alkol madde kullanım alışkanlıklarının bulunması şiddete yönelme ve ruh sağlı̆̆ üzerinde etkili olmakta ve risk grubu olarak görülmektedir.

Üniversitelerde sigara, alkol ve madde kullanan, depresyon ve anksiyete açısından risk grubu olarak kabul edilen ve şiddet eğilimi olan öğrencilere yönelik önleyici ve iyileştirici programların yapılması, öğrencilere olumsuz başetme yöntemlerinden olan sigara, alkol ve madde kullanımı olmadan öfke kontrollerinin sağlanması ve bu şekilde şiddet eğilimlerinin azaltılması için girişimsel çalışmaların yapılması önerilmektedir. 
Araştırmanın Sınırılıkları: Çalışma sadece bir kamu üniversitesinin Sağlık Bilimleri Fakültesi öğrencileri ile sınırlıdır. Çalışmada evrenin tamamına ulaşılması hedeflenirken çalışmanın yapıldığı gün ve saatlerde derse devam eden öğrenciler ile sınırlıdır.

\section{Finansal destek}

Finansal destek alınmamıştır.

\section{Çıkar Çatışması}

Yazarlar arasında çıkar çatışması bulunmamaktadır.

\section{Yazarlık Katkıları:}

Tasarım/Design: F.H., N.G.M.; Veri Toplama veya Veri Girişi Yapma/Data Collection or Processing: NGM Analiz ve Yorum/Analysis or Interpretation: F.H., N.G.M.; Literatür Tarama/Literature Search: F.H., N.G.M.;Yazma/Writing: F.H., N.G.M.

\section{KAYNAKÇA}

Alaçam, H., Çulha Ateş, F., Şengül, A. C., \& Tümkaya, S. (2015). Üniversite öğrencilerinde internet bağımlılığının sigara ve alkol kullanımı ile ilişkisi. Anadolu Psikiyatri Derg., 16(6), 383-388.

Albayrak, S., \& Balcı, S. (2014). Gençlerde Madde Bagımlılıgı ve Önlenmesi, Hemsırelıkte Eğitim ve Araştırma Dergisi, 11(2), 30-37.

Assari, S., \& Lankarani, M. M. (2018). Violence exposure and mental health of college students in the united states, Behav. Sci., 8,53, 2-14. doi:10.3390/bs8060053

Baysan Arabacı, L., Taş, G., \& Dikeç, G. (2017). Çocuk ve ergenlerde madde kullanımı, suça yönelme, ruhsal bozukluklar ve hemşirelik bakımı, Bağımlılık Dergisi - Journal of Dependence, 18(4), 135-144.

Baran, M., Küçükakça, G., Ayran, G. (2014). Sağlık yüksekokulu öğrencilerinde algılanan sosyal destek düzeyinin sigara kullanımı üzerine etkisi. ADÜ Tıp Fakültesi Dergisi, 15(1), 9-15.

Bostanci, M., Özdel, O., Oguzhanoglu, N. K., Özdel, L., Ergin, A., Ateş̧̧i, F., \& Karadağ, F. (2005). Depressive symptomatology among university students in denizli, Turkey: prevalence and sociodemographic correlates. Croat Med. J., 46(1), 96-100.

Cénata, J. M., Blaisb, M., Lavoiec, F., Carond, P. O., \& Hébertb, M. (2018). Cyberbullying victimization and substance use among Quebec high schools students: The mediating role of psychological distress, Computers in Human Behavior, 89, 207-212. https://doi.org/10.1016/j.chb.2018.08.014

Donat Bacığlu, S. (2014). Şiddet ve saldırganlığın azaltılmasında önleme ve müdahale programlarının etkililiği: meta analiz çalışması. Türk Psikolojik Danışma ve Rehberlik Dergisi, 5(42), 294-304.

Eronen, M., Angermeyer, M. C., Schulze, B. (1998). The psychiatric epidemiology of violent behaviour, Soc Psychiatry Psychiatr Epidemiol, 33:13-23.

Erdal, H., Doğan, H. G., \& Ağcadağ, D. (2013). Üniversite öğrencilerinin alkol kullanma durumları ve bunu etkileyen faktörlerin analizi (Gaziosmanpaşa Üniversitesi örneği). International Journal of Social and Economic Sciences (IJSES), $1,95-99$.

European School Survey Project on Alcohol and Other Drugs (ESPAD) Group. ESPAD Report 2015. Retrieved from http://www.espad.org/report/home

Evren, H., Tokuç, B., Ekuklu, G. (2011). Trakya Üniversitesi öğrencilerinde şiddet davranışları ve algılanan sağlık ilişkisi. Balkan Med J., 28, 380-384.

Gençoğlu, C., Kumcağız, H., \& Ersanlı, K. (2014). Ergenlerin şiddet eğilimine etki eden ailevi faktörler. Turkish Studies, 9(2), 639-652. http://dx.doi.org/10.7827/TurkishStudies.6208

Göney, G., Gazeloğlu C. \& Nal, M. (2020). Association between smoking exposure, and obesity in Turkey, Genel Sağllk Bilimleri Dergisi, 2(2), 19-27.

Güleç, G., Köşger, F., \& Eşsizoğlu, A. (2015). DSM-5'te Alkol ve madde kullanım bozuklukları. Psikiyatride Güncel Yaklaşımlar, 7(4), 448-460. doi: 10.5455/cap.20150325081809

Gümüş Babacan, A., Sıpkın, S., Tuna, A., \& Keskin, G. (2015). Üniversite öğrencilerinde problemli internet kullanımı, şiddet eğilimi ve bazı demografik değişsenler arasındaki ilişki. TAF Prev Med Bull, 14(6), 460-467.

Haskan Avcı, Ö., \& Yıldırım, İ. (2014). Ergenlerde şiddet eğilimi, yalnızlık ve sosyal destek. H. U. Journal of Education, 29(1), 157-168.

İlhan, N., Bahadırlı, S., \& Ercan Toptaner, N. (2014). Üniversite öğrencilerinin ruhsal durumları ile sağlık davranışları arasındaki ilişkinin belirlenmesi. MÜSBED, 4(4), 207-215. DOI: 10.5455/musbed.20140913124019

Kaplan, V., \& Çuhadar, D. (2020). The levels of anger and aggression in street children with substance dependence, J Child Adolesc Psychiatr Nurs, 33:239-247. DOI: 10.1111/jcap.12275 
Kaya, M., Genç, M., Kaya, B., \& Pehlivan E. (2007). Tıp fakültesi ve sağlık yüksekokulu öğrencilerinde depresif belirti yaygınlığı, stresle başa çıkma tarzları ve etkileyen faktörler. Türk Psikiyatri Dergisi, 18(2), 137-146.

Kılıç, C. (1996). Genel sağlık anketi: güvenilirlik ve geçerlilik çalışması. Türk Psikiyatri Dergisi, 7(1), 3-10.

Kolay Akfert, S., Çakıcı, E., \& Çakıcı, M. (2009). Üniversite öğrencilerinde sigara-alkol kullanımı ve aile sorunları ile ilişkisi. Anadolu Psikiyatri Derg, 10, 40-47.

Köse Tosunöz, İ., Öztunç, G., Eskimez, Z., \& Yeşil Demirci, P. (2019). Determination of nursing students' tendency to violence Hemşirelik öğrencilerinin şiddet eğilimlerinin belirlenmesi. Cukurova Med J., 44(2), 471-478. DOI: 10.17826/cumj. 459256

Kul Uçtu, A. \& Karahan, N. (2016). Sağlık yüksekokulu öğrencilerinin cinsiyet rolleri, toplumsal cinsiyet algısı ve şiddet eğilimleri arasındaki ilişkinin incelenmesi, İnsan ve Toplum Bilimleri Araştırmaları Dergisi, 5(8), 2882-2905.

Lenz, B. K. (2004). Tobacco, depression, and lifestyle choices in the pivotal early college years. Journal of American College Health, 52(5), 213-219. doi: 10.3200/JACH.52.5.213-220.

Mackenzie, S., Wiegel, J. R., Mundt, M., Brown, D., Saewyc, E., Heiligenstein, E., Harahan, B., \& Fleming, M. (2011). Depression and suicide 1deation among students accessing campus healthcare. Am J Orthopsychiatry, 81(1), $101-107$. https://doi.org/10.1111/j.1939-0025.2010.01077.x

Mayda, A. S., Gerçek, Ç. G., Güneş, C., Hüseyinoğlu, A., Giler, M. B., \& Yıldırım, A. (2009). Tıp fakültesi öğrencilerinde depresif belirti sıklığının demografik özellikler, sigara, alkol, madde kullanımı, baskın el ve şiddete maruz kalma ile ilişkisi. Tubav Bilim Dergisi, 2(4), 476-483.

Merrin, G. J., Thompson, K., \& Leadbeater, B. J. (2018). Transitions in the use of multiple substances from adolescence to young adulthood. Drug and Alcohol Dependence, 189(May), 147-153. https://doi.org/10.1016/j.drugalcdep.2018.05.015

Mikolajczyk, R. T., Maxwell, A. E., El Ansari, W., Naydenova, V., Stock, C., İlieva, S., Dudziak, U., \& Nagyova, I. (2008). Prevalence of depressive symptoms in university students from germany, Denmark, Poland and Bulgaria. Soc Psychiatry Psychiatr Epidemiol, 43(2), 105-112. DOI: 10.1007/s00127-007-0282-0

On Birinci Kalkınma Planı 2019-2023. https://www.sbb.gov.tr/wp-content/uploads/2019/11/ON_BIRINCI_KALKINMAPLANI_2019-2023.pdf

Özcan, A., Şermet Kaya, Ş., Özdil, K., Küçük Öztürk, G., Sezer, F., Niğdelioğlu, D., Yaşar, Z. (2020). Lise öğrencilerinde şiddet eğilimi ve ilişkili faktörler; Halk Sağlığı Hemşireliği Dergisi, 2(1): 2-13.

Özgür, G., Yörükoğlu, G., \& Baysan Arabac1, L. (2011). Lise öğrencilerinin şiddet algıları, şiddet eğilim düzeyleri ve etkileyen faktörler. Psikiyatri Hemşireliği Dergisi, 2(2), 53-60.

Pereira- Morales, A. J., Adan, A., Camargo, A. \& Forero, D. A. (2017). Substance use and suicide risk in a sample of young colombian adults: an exploration of psychosocial factors, The American Journal on Addictions, 26: 388-394, DOI: 10.1111/ajad.12552

Roberts, S. J., Glod, C. A., Kim, R., \& Hounchell, J. (2010). Relationships between aggression, depression, and alcohol, tobacco: Implications for healthcare providers in student health. Journal of the American Academy of Nurse Practitioners, 22(7), 369-375.

Shackleton, N., Jamal, F., Viner, R., Dickson, K., Hinds, K., Patton, G., \& Bonell, C. (2016). Systematic review of reviews of observational studies of school-level effects on sexual health, violence and substance use. Health\&Place, 39, 168-176. doi: 10.1016/j.healthplace.2016.04.002.

Strauss, C. V., Haynes, E. E., Cornelius, T. L., \& Shorey, R. C. (2019). Stalking victimization and substance use in college dating relationships: an exploratory analysis, Journal of Interpersonal Violence, 34(14), $2878-2896$. https://doi.org/10.1177/0886260516663899

Şahin Baltacı, H., \& Altan, T. (2016). Lise öğrencilerinde benlik saygısının yordayıcısı olarak depresyon, bağlanma ve şiddet eğilimi, Mehmet Akif Ersoy Üniversitesi Eğitim Fakültesi Dergisi, 40, 227-239.

Sutherland, R., Sindicich, N., Barrett, E., Whittaker, E., Peacock, A., Hickey, S., \& Burns, L. (2015). Motivations, substance use and other correlates amongst property and violent offenders who regularly inject drugs, Addict Behav., 45:207-13.

Taylor, K. A., \& Sullivan, T. N. (2017). Bidirectional relations between dating violence victimization and substance use in a diverse sample of early adolescents. Journal of Interpersonal Violence, 0(0), 1-30. DOI: 10.1177/0886260517731312

T.C. Başbakanlık Aile Araştırma Kurumu. Aile içinde Şiddet ve Toplumsal Alanda Şiddet. Ankara, Başbakanlık Basımevi, 1998.

The United Nations Office on Drugs and Crime (UNODC). (2019). World Drug Report 2019 Booklet 1-2. Retrieved from https://wdr.unodc.org/wdr2019/

Towsend, M. C. (2016). Madde ile ilişkili bozukluklar (D. Hiçdurmaz, 6nd ed.) Ruh Sağlığı ve Psikiyatri Hemşireliğinin Temelleri. Akademisyen Tip Kitapevi, Ankara, 278-334.

Türkiye Uyuşturucu ve Uyuşturucu Bağımlılı̆̆ İzleme Merkezi (TUBİM), Türkiye Uyuşturucu Raporu 2019.(http://www.narkotik.pol.tr/kurumlar/narkotik.pol.tr/TUB\%C4\%B0M/Ulusal\%20Yay\%C4\%B1nlar/2019TURKIYE-UYUSTURUCU-RAPORU.pdf ) erişim tarihi:23.09.2020 st:23:00

Turhan, E., İnand1, T., Özerb, C., \& Akoğluç, S. (2011). Üniversite öğrencilerinde madde kullanımı, şiddet ve bazı psikolojik özellikler. Türkiye Halk Sağlığı Dergisi, 9(1), 33-44.

Ulaş, B., Tatlıbadem, B., Nazik, F., Sönmez, M., \& Uncu, F. (2015). Üniversite öğrencilerinde depresyon sıklığı ve ilişkili etmenler. Celal Bayar Üniversitesi Sağlık Bilimleri Enstitüsü Dergisi, CBU-SBED, 2(3):71-75.

Uras, C., Gennaro, R., Aparo, U L., \& Tabolli, S. (2012). Risk of anxiety and depression in nursing students in Rome (Italy). Ig Sanita Pubbl, 68(4), 555-64. 
Uzbay, İ. T. (2009). Bağımlılık yapan maddeler ve özellikleri. Meslek İçi Sürekli Eğitim Dergisi, (21-22), 16-33. https://www.teb.org.tr/versions/61

Üner, S., Bağcı Bosi, T., Velipaşaoğlu, M., Üre, İ., Topbaşı, Z. H., Varol, R. S., Sungur, M.A., \& Sanhal, C. Y. (2007). Ankara'da bulunan iki lisenin öğrencilerinin ruhsal durumlarının GSA-12 ile değerlendirilmesi. Toplum Hekimliği Bülteni, 26(1), 25-31.

Ünsal, A., \& Tözün, M. (2014). Türkiye'nin batısında kırsal bir alanda erişkin erkeklerde sigara içme ve depresyon ilişkisi. TAF Prev Med Bull, 13(4), 273 - 280. DOI: 10.5455/pmb1-1360386445

Yalçın, M., Eşsizoğlu, A., Akkoç, H., Yaşan, A., \& Gürgen, F. (2009). Dicle Üniversitesi öğrencilerinde madde kullanımını belirleyen risk faktörleri. J Clin Psy., 12, 125-123.

Yan, D. M., L1, D. L., Zhao, H. H., \& Sh1, M.Y. (2019). Investigation and analysis on the physical and mental health status of intern nurses in a hospital. Gansu Province, Journal of Integrative Nursing, 1(3), 138-142. doi: 10.35437/intnur.issn.26634481.2019.01.03.03

Yıldız, D., Çiftçi, A., Yalçın, Ö. (2020). Bir çematem kliniğinde yatan ergen hastalarda madde kullanım eğilimleri, psikososyal travmalar, psikiyatrik komorbiditeler ve cinsiyet farklılıkları, Düşünen Adam The Journal of Psychiatry and Neurological Sciences, 33, 190-202. DOI: 10.14744/DAJPNS.2020.00078

Yılmaz, A., Can, Y., Bozkurt, M., \& Evren, C. (2014). Alkol ve madde bağımlılı̆̆ında remisyon ve depreşme. Psikiyatride Güncel Yaklaşımlar, 6(3), 243-256. doi:10.5455/cap.20131114113549

Yiğit, Ü., \& Öncü, E. (2019). Çalışan gençlerde sigara, alkol, uyuşturucu/uyarıcı madde kullanımı ve risk faktörleri. Addicta: The Turkish Journal on Addictions, 6(4), 49-66. http://dx.doi.org/10.5152/addicta.2020.19081

Zinnur Kılıç, E. (2012). Ergenlerde şiddet kullanımı: bireysel ve ailesel etkenler. Nöropsikiyatri Arşivi, 49(4), $260-265$. https://doi.org/10.4274/npa.y6100 


\section{EXTENDED ABSTRACT}

Introduction: The use of addictive substances all over the world and in our country is a public health problem that is becoming increasingly important. Alcohol and substance use can cause psychiatric disorders, as well as additional problems such as a tendency to violence and crime. Turhan et al. (2011) in their study with university students, they found that the rate of violence and exposure to violence was high in those who used cigarettes, alcohol and substances. In the literature, while there are separate studies on psychological factors, violence and substance use among university students (Baran et al., 2014; Erdal et al., 2013; Özgür et al., 2011), there were not enough studies examining the relationship between them (Turhan et al., 2011). Therefore, in this study, it is aimed to determine the substance use status, mental state and violence tendency levels of the students of Health Sciences Faculty.

Materials and Methods: It is a descriptive study. Population of the study is composed of the students registered in a University, Faculty of Health Sciences, and whole population is included within the sample. The universe of research consists of 573 students enrolled in the Faculty of Health Sciences of a public university. The sample of the study consisted of 422 students (73.64\%) who agreed to participate in the study, continued the lesson during the course time of the study and completed the data collection form completely. Research data was collected after obtaining the necessary permission of the institution and the consent of the students. Data were collected with personal information form, violence tendency level scale and General Health Questionnaire. Each class was attended once, and students who were in class that day were included in the study. Each form took about 15 minutes to apply, and students filled out the forms themselves. Data were analyzed by using tests of numeric, percentage, Mann Whitney U, Kruskall Wallis, Chi square and Spearman's correlation in SPSS program.

Findings: Totally 422 cases were evaluated in the trial. Our analysis showed that $40.5 \%$ of the students participants were nursing students, $76.8 \%$ were women, $94.3 \%$ were parents alive and $91 \%$ lived with their parents, the vast majority of the 'educational level was at primary school level ( $83.2 \%$ of the mother, $55.7 \%$ of the father), $60.2 \%$ were evaluated as equivalent to income expenses, $80.1 \%$ received their allowance from their family.

According to the research findings it was confirmed that 65.9 of the students smoke, $9.2 \%$ of them consume alcohol and $4.1 \%$ substance use. In studies, smoking rates were between $73.3 \%$ and $33.3 \%$, alcohol use rates were between $26.3 \%$ and $70.8 \%$, and volatile and drug use rates were between 1.78\% and 6.3\% (Straus et al., 2019; TUBIM 2019; Alaçam et al., 2015; Turhan et al., 2011; Universe et al., 2011; Mayda et al., 2009; easy Akfert et al., 2009; Yalcin et al., 2009).

$74.9 \%$ of the students who participated in the study have General Health Questionnaire-28 grade of 4 and above 4 , and determined to be in the risk group of non-psychotic depression and anxiety. İt was confirmed that $38.6 \%$ of the students participated in the study had high level of tendency to violence.

As a result of the Spearman's correlation coefficient technique, which was conducted to determine the relationship between the Violence Tendency Scale and the General Health Questionnaire scores, it was determined that there was a significant and positive correlation (r: 0.354, p:0.000) between the variables between the Violence Tendency Scale score and the General Health Questionnaire score.

Faculty of Health Sciences students who study in the Department of nutrition and Dietetics (n: 46, 82.1\%, p:0.001) and those whose gender is female (n: $23,7.1 \%$, p:0.000) it was found that the conditions of experiencing smoking were significantly higher compared to the chi square test. The levels of lifetime alcohol use (n: 16, 16.3\%, p:0.003) and experiencing drugs (n: 5, $5.1 \%$, p:0.009) were found to be higher in men. Students' Violence Tendency Scale scores were found significantly higher for males than females (p:0.002).

The education status of the father affects the students' general health questionnaire scores. If the father's education level is secondary, the risk of depression and anxiety increases (p:0.037). Those with low monthly income of the family are at higher risk for depression and anxiety (p:0.001). General Health Questionnaire scores; students who smoke daily are higher than those who use occasionally (p:0.004). General Health Questionnaire scores; It was determined that those whose relatives had drug use were statistically significantly higher than those who did not (p:0.001). In addition, it was found that, in the last month, both the Violence Tendency Scale (p:0.004) and General Health Questionnaire (p:0.001) scores of the occasional alcohol users were statistically significantly higher than the non-users.

Conclusions and Suggestions: It have been determined that students of Faculty of Health Sciences experienced smoking, alcohol and substance use, they are in the risk group in terms of depression and anxiety from mental illness, and they have tendency to violence. It is recommended to conduct preventive and curative programs for university students, provide students with anger control without smoking, alcohol and substance use, which are negative methods of coping, and thus conduct interventional studies to reduce violent tendencies. Preventive programs are recommended for university students on issues such as coping with stress, crisis management, problem solving, anger management, peer mediation, assertiveness training, conflict resolution, problem solving, etc. 